\title{
Assessment of Land Use And Land Cover Change Detection And Prediction Using Remote Sensing And CA Markov In The Northern Coastal Districts of Tamil Nadu, India
}

Devanantham abijith

National Institute of Technology Tiruchirappalli

Subbarayan Saravanan ( $\nabla$ ssaravanan@nitt.edu )

National Institute of Technology Tiruchirappalli https://orcid.org/0000-0003-4085-1195

\section{Research Article}

Keywords: Google Earth Engine, Random Forest, Land use and land cover, CA- Markov, Land change modeler, Geographical Information System, Remote sensing

Posted Date: June 11th, 2021

DOI: https://doi.org/10.21203/rs.3.rs-576976/v1

License: (1) This work is licensed under a Creative Commons Attribution 4.0 International License.

Read Full License 


\section{Abstract}

Land use and land cover (LULC) change analysis and forecasting aids the upcoming generation in research and evaluate the global climate change for managing and controlling environmental sustainability. This research analyzes the Northern TN coast, which is under both natural and anthropogenic stress. The analysis of LULC changes and LULC projections for the region between 20092019 and 2019-2030 was performed utilizing Google Earth Engine (GEE), TerrSet, and Geographical Information System (GIS) tools. LULC image is generated from Landsat images and classified in GEE using Random Forest (RF). LULC maps were then framed with the CA-Markov model to forecast future LULC change. The CA-Markov's Land change modeler (LCM) was set up to create future LULC. It was carried out in four steps: (1) Change analysis, (2) Transition potential, (3) Change prediction, and (4) Model validation. For analyzing change statistics, the study region is divided into zone 1 and zone 2. In both zones, the water body shows a decreasing trend, and built-up areas are in increasing trend. Barren land and vegetation classes are under stress and developing into built-up. The overall accuracy was above $89 \%$, and the kappa coefficient was above $87 \%$ for all three years. This region is highly susceptible to inland floods, coastal floods, and other natural disasters; thus, this study's results support future development plans and decision-making.

\section{Introduction}

The development of urbanization and industrialization led to the change in land use and land (LULC) in the last two centuries resulting in the degradation of the sustainable conditions for the future. This intense urbanization does not follow a linear trend (Bose \& Chowdhury, 2020). Few cities in the world have established planned layouts for urban distributions. Over time, low-density built-up regions become high-density and later extremely density regions because of the increasing land demand due to changes in the desirability of the communities (Saxena \& Jat, 2020). LULC transition is a critical issue while analyzing global trends as they impact groundwater infiltration, evapotranspiration, and natural disaster (Tewabe \& Fentahun, 2020). The controlling mechanism of urban development involves assessing the time-space relationship between nonlinear interactions such as culture, economy, topography, population, land use, and river systems. (Thapa \& Murayama, 2011).

India is the second-populous country with 1.3 billion in 2015 and the seventh-largest country in the world. Over the last 140 years, India has seen drastic shifts in LULC, including a reduction in the forest, change in cropland, and an increase in urbanization). This practice continued till the 1960s, when, for the first time, the 'Green Revolution' limited itself to increasing crop production, irrigation, and the use of fertilizer and pesticides (Abrol et al., 2002; Roy et al., 2015). UN estimates show that 60 percent of the world's rural villages will be covered by large cities in 2050 . This is due to unplanned urban growth caused by a lack of planning and development (Bose \& Chowdhury, 2020). Spatial modeling can be used to investigate the complexities of potential agricultural production, associated LULC change, and environmental consequences. Anthropogenic and environmental mechanisms need to be thoroughly understood concerning the temporal dynamics and possible changes in land cover (Chughtai et al., 2021; Silva et al., 
2020). Urban growth would be beneficial for urban planners and engineers; furthermore, recognizing the future trends and extent of urban development would be crucial for open space and natural habitat protection (L. Singh et al., 2021).

The emergence of remote sensing (RS) has led to various land use studies, such as the evolution of LULC in a global environment and evaluating the transition of various land types (Ghosh et al., 2017). Satellite remote sensing has the advantages of comprehensive coverage, extensive collections of data, and ongoing observations (Hu et al., 2018). RS and Geographical Information Systems (GIS) are effective methods for obtaining precise and temporal information on the spatial distribution of LULC over large areas. When analyzed in RS, ground surfaces have a distinct spectral signature, referred to as spectral reflectance patterns (Becker et al., 2021). GIS offers a robust framework in which digital change detection information is collected, stored, displayed, and analyzed. Landsat 5, 7, and Landsat 8 were commonly employed for LULC analysis because of their moderate or high-resolution images and continuous global coverage (since 1972) (Alam et al., 2020).

Over the last decade, RS data processing has shifted from conventional workstations to cloud-based platforms that enable users to access and analyze geospatial data through user-friendly cloud interfaces and programming languages (Tassi \& Vizzari, 2020). Google Earth Engine (GEE) is a cloud-based platform to extensively compute satellite data for research, education, and non-profit applications. GEE can be accessed using a JavaScript code editor platform, and it simplifies the processing of satellite imagery. A quick sign-in to your Google account is enough to gain access to the GEE (Gorelick et al., 2017a; Midekisa et al., 2017; Sidhu et al., 2018a; Tsai et al., 2018; Wagle et al., 2020). Earth Engine has a variety of supervised and unsupervised classifications, including machine-based learning algorithms for the mapping implementation. The data available covers a wide range of satellites, including the Sentinel series; Moderate Resolution Imaging Spectrometer (MODIS); Landsat series; Advanced Land Observing Satellite (ALOS); National Oceanographic and Atmospheric Administration Advanced very high-resolution radiometer (NOAA AVHRR), etc., (Kumar \& Mutanga, 2018). The data is relatively accessed and can be conveniently downloaded or stored in the cloud. GEE is utilized in several disciplines to solve different environmental issues such as forest fire and changes in the forest (Seydi et al., 2021; Ye et al., 2021), surface water area change (Yang et al., 2020), estimation of crop yield (Cao et al., 2021; Tian et al., 2020), urban mapping (Ji et al., 2020; Zhang et al., 2021), flood mapping (Pourghasemi et al., 2021; Tiwari et al., 2020) and few studies for fire recovery (Huang et al., 2017; Soulard et al., 2016), mangrove mapping (de Jong et al., 2021), drought analysis (Khan \& Gilani, 2021).

Idrisi TerrSet is an automated geospatial information framework that researchers commonly use to analyze and model earth system processes for sustainable development (Nath et al., 2020). Land change modeler (LCM) is an important tool for environmental and other learning scenarios on LULC change in TerrSet. It is used to analyze the historical and forecast potential LULC changes. The extent and direction of LULC are two major factors that have been considered in the modeling. Models for assessing LULC transition may be static or dynamic, inductive or deductive, agent-based or pattern-based, spatial or nonspatial (V. N. Mishra \& Rai, 2016; Noszczyk, 2019; Ozturk, 2015; Zadbagher et al., 2018). The Cellular 
Automata (CA)-Markov model is stochastic and assesses the likelihood that a state will switch to a different state that is, the condition time $t_{2}$ is predicted from the time $t_{1}$. LCM analyses the changes in LULC over various periods, calculates, visualize, and displays the changes using several maps and graphs (Aburas et al., 2017; Noszczyk, 2019).

CA-Markov model using TerrSet software is used in this analysis to simulate LULC changes and urban growth prediction on the northern Tamil Nadu (TN) coast, India. According to the international scientific community, there is a chance that by 2050 , few centimeters of sea-level increase will occur in the districts of Tiruvallur, Chennai, Kanchipuram, Villupuram, Cuddalore, and several other districts. This research aims to detect the urban growth pattern and recognize the future growth scenario using simulations in the LCM. These simulations were used to predict the urban growth in 2019, 2025, 2030 using LULC from 2009 and 2015. Transition directions and spatial variations of potential changes from 2009 to 2030 were calculated.

\section{Material And Methods}

\subsection{Study area}

Tamil Nadu (TN) is situated in the southern part of India, and its coastline stretches for about $1076 \mathrm{~km}$. It accounts for nearly $15 \%$ of India's overall coastal length and extends along the Bay of Bengal and the Indian Ocean (Parthasarathy et al., 2020; Parthasarathy \& Deka, 2019). The study region's climate is mostly tropical semiarid. Its geographical location makes it one of the country's most fragile coastal states, especially in tropical cyclones and the storm surges that accompany them. It is often subjected to adverse conditions, such as flooding in coastal areas (Saranya \& Saravanan, 2020, 2021). The research focuses mainly on changes in the LULC for a distance of $25 \mathrm{~km}$ landward from its administrative boundary along the northern coast of TN. The study area covers $6447.12 \mathrm{~km}^{2}$, including 5 districts of TN (Tiruvallur, Chennai, Kanchipuram, Villupuram, Cuddalore) and one union territory (Pondicherry), with elevation ranging from sea level is $210 \mathrm{~m}$ (Fig. 1). Summer temperatures rarely exceed $45^{\circ} \mathrm{C}$, and winter temperatures rarely dip below $20^{\circ} \mathrm{C}$. Temperatures and humidity remain consistently high throughout the year. The study receives its major downpour during the northeast (NE) monsoon season. The average rainfall is about $950 \mathrm{~mm}$ and receives approximately $48 \%$ of the annual average rainfall during the NE monsoon (October-December). The region has two major ports, two minor ports, fishing harbors, and a host of coastal industries such as nuclear and thermal power plants, refineries, fertilizer plants.

Mangroves, mudflats, and sand dunes are among the coastal habitats found along the coast. The rivers run from west to east, eventually reaching the Bay of Bengal. The Cauvery and Pennar rivers are among the most prominent. The largest estuary is the Cauvery River, and smaller estuaries include Vellar, Pazhayar, and Adyar.

\subsection{Data sources}


The aim is to analyze LULC changes and their resultant urban growth along the northern coast of TN. For the study, various spatial databases were developed to model the LULC and its urban growth using various parameters. The parameters are derived from various sources, as shown in table 1.

Table 1. Data sources

\begin{tabular}{lll} 
Parameters & Data source & Source location \\
\hline LULC & $\begin{array}{l}\text { Landsat 5 \& 8 using } \\
\text { GEE }\end{array}$ & https://code.earthengine.google.com/ \\
$\begin{array}{l}\text { Digital elevation } \\
\text { model }\end{array}$ & ASTER DEM & https://lpdaac.usgs.gov/products/astgtmv003/ \\
\hline Slope & ASTER DEM & https://lpdaac.usgs.gov/products/astgtmv003/ \\
\hline Road Network & OpenStreetMap & https://www.openstreetmap.org/\#map=6/10.488/74.597
\end{tabular}

LULC maps have been categorized in the GEE platform using Random Forest (RF) algorithm. GEE allows web access to archived Landsat images for the current study. To create the LULC maps for the year 2009, Landsat 5 was used. For the years 2015 and 2019, Landsat 8 was used. Near-Infrared (NIR), Red, Green, and Blue bands are stacked to generate true-color composite and false-color composite. The RF classification was carried out using a set of training samples in each class. The classified maps were validated using the set of testing samples.

LULC forecasting is carried out using Idrisi TerrSet software. The Land Change Modeller (LCM), a tool for projecting a land change in TerrSet, is used. It maps potential possibilities of change by empirically modeling the relationship between land cover changes and the potential driver variables based on historical land cover change. Hence, the driver variables such as Digital Elevation Model (DEM), slope, road map, and built-up maps were prepared. The Advanced Spaceborne Thermal Emission and Reflection Radiometer (ASTER) DEM with a resolution of $30 \mathrm{~m}$ is used. The slope is derived from ASTER DEM and processed using an ArcGIS environment. The Road network is an important parameter for the LULC prediction and is derived from the OpenStreetMap, and distance from road is processed using ArcGIS. The built-up is extracted from the 2019 classified LULC image, and the distance from the built-up is processed using ArcGIS. The spatial resolution of all these datasets was set to the same as that of Landsat images $(30 \mathrm{~m})$.

\subsection{Google Earth Engine environment}

GEE is a geospatial processing tool with a cloud-based platform for a wide-ranging environment study and interpretation. The GEE is a web-based Graphical User Interface (GUI) that provides access to a multipetabyte catalog of RS imagery and other datasets through Google's computational infrastructure. For popular coding languages like JavaScript and Python, a set of Application Programming Interfaces (APIs) and development environments are available. These key features, when combined, enable users to explore, interpret, and simulate geospatial big data in powerful ways (Gorelick et al., 2017b; Kumar \& 
Mutanga, 2018; Sidhu et al., 2018b; Tamiminia et al., 2020). Figure 2 shows the process carried out in the GEE environment.

\subsubsection{LULC mapping}

GEE makes it easier to specify different modes of operation for combining input data, efficiently generating composite data, cloud-free, and multi-temporal datasets (Tassi \& Vizzari, 2020). The classifier performs supervised classification using Earth Engine's standard Machine Learning (ML) algorithms. Classification and Regression Trees (CART), Random Forest (RF), Naive Bayes, and Support Vector Machine (SVM) are among the classifiers. In GEE, the Cluster package performs unsupervised classification. This study utilizes a pixel-based supervised classification using a machine learning algorithm (RF) for land cover classification.

Random Forest -Ensemble (such as random forest, bagging, and boosting) are gaining popularity as they're more reliable and robust to noise than classification models. Classifier ensembles are based on the simple assumption that a collection of classifiers performs preferable classifications than a single classifier. Breiman (2001) proposed an ambitious classifier called a random forest, which has several benefits for remote sensing applications. (Breiman, 1996, 1999; Rodriguez-Galiano et al., 2012). The formation of decision trees, which make up the forest, is crucial to the functioning of RF. This is done in two steps. First, each tree is created by selecting samples at random, which implies that each tree in the forest is trained with unique samples of the same size. The trees are trained using several training sets, with the remaining one-third utilized in cross-validation to determine the efficiency of the RF model. The splitting constraints for each node in the trees are obtained in the second step by comparing predictor variables (Chakraborty et al., 2016; Colkesen \& Kavzoglu, 2017; Smith, 2010).

Tree structure generally requires the choice of an appropriate attribute selection that maximizes the differences among the class. There are several estimators for choosing attributes for induction in decision trees. Gain-ratio, Gini Index, and Chi-square are three of the most common. The RF would typically use the Gini Index to find the best split range, which determines the impurity of a given variable compared to the rest of the classes. For a given training dataset $\mathrm{T}$, the Gini index can be expressed as follows:

$$
\sum \sum_{i+j}\left(f\left(c_{i}, T\right) /|T|\right)\left(f\left(C_{j}, T\right) / T D\right.
$$

Where $f\left(c_{i} T\right) / \mid T$ is the likelihood that a given case belongs to the $C_{i}$ class.

Consequently, a decision tree is formed that uses a specific combination of characteristics to extend to its full depth (with no pruning). According to research, the selection of pruning techniques, rather than the selection of attribute selection steps, has a greater effect on the success of tree-based methods. As a result, RF development without being pruned is an additional benefit (Rodriguez-Galiano et al., 2012).

\subsubsection{Accuracy assessment}


Accuracy assessment helps to understand how precise the maps are to use the data accurately and effectively. Failure to attain the expected target levels of precision is commonly interpreted as a lack of satellite data classification against LULC. Various algorithm's accuracy was evaluated using metrics obtained from an error matrix, such as Overall Accuracy (OA), Producer Accuracy (PA), Consumers Accuracy (CA), and kappa coefficient (KC) (Abdi, 2020; Foody, 2002). Below, equations are used for acquiring accuracy.

Overall accuracy $(\mathrm{OA})=$ Total number of correct samples- $100 \%$ total number of samples $(2)$

Producer accuracy $(P A)=100 \%$ - error of omission (\%) (3)

Consumer's accuracy $(C A)=100 \%$ - error of commission (\%) (4)

Kappa coefficient $(\mathrm{KC})=\frac{\sum a-\sum e f}{N-\sum e f}$

Where " $a$ " denotes Diagonal frequency, " $N$ " denotes total frequency and "ef" denotes expected frequency.

\subsection{LULC prediction model}

The changes between two different time intervals were estimated in the change analysis. Cellular automation is a cellular entity that is based on the proximity theorem, which says that areas that are closer to current areas of the same class are more likely to move on to a new class, as defined by the Markov transition rules and related neighborhoods (S. K. Singh et al., 2015). This architecture is based on artificial neural networks (ANN), MC matrices, and changeover suitability maps developed by MLP training (Ansari \& Golabi, 2019; Hasan et al., 2020). Figure 3 shows the process carried out from the resultant LULC maps to predict the future LULC for 2025 and 2030.

This study forecasts future changes in land use and land cover in four phases: (1) Change analysis: The differences over two different periods examine it. By mapping gains and losses within distinct land cover classes, the change analysis gives a simple quantitative change (Al-sharif \& Pradhan, 2014; Gibson et al., 2018) (2) Transition potential: The transition potential determines the area of change. Land cover transitions may be divided into sub-models if the underlying drivers of transition are the same for each transition (Megahed et al., 2015; Pérez-Vega et al., 2012). (3) Change prediction: This model estimates the future LULC from time $t=1$ to time $t+1$ based on the transition probability matrix and the transition area matrix of each LULC class. The transition probability map determines the likelihood of each pixel converted from one land cover to another or remain unchanged throughout the year (Hasan et al., 2020; Müller et al., 2010). (4) Model validation: To evaluate the accuracy, model validation is needed. Thus, the validation process aims to compare the accuracy of the 2019 projected map to the 2019 classified LULC map (Chaudhuri \& Clarke, 2014). The following explanatory variables were chosen based on improvements in land cover driving forces: (a) DEM, (b) Slope, (c) distance from road, (d) distance from built-up. The ANN was performed after the transition classes were specified. The method's consistency is determined by the number of iterations between the explanatory variables and the transitions under 
consideration. The default interface was used. A sample of $50 \%$ used for training, with the remaining $50 \%$ kept for validation (Silva et al., 2020). The predicted were compared to the classified using the Kappa index statistic (Al-sharif \& Pradhan, 2014; Cunha et al., 2021).

\section{Results}

\subsection{Analysis of LULC classification}

LULC statistics and transition patterns help analyze the changes and investigate the forces behind the shifts in LULC. Land-use transition study focused on the northern coast of TN for the years 2009, 2015, and 2019 using the RF Algorithm. RF is a tree-based classifier that is adaptive to both random and systematic classification. It is essential to define the space dimensionality of a random sample and the number of trees to be constructed based on the decision; thus, the number of trees set to 30 . The results were categorized to study the changes in LULC and its associated urban growth. The study area is divided into two zones: Zone 1 (Z1) and Zone 2 (Z2), five primary classifications, i.e., waterbody, built-up, vegetation, forest, and barren land. Here water body includes lake systems, rivers, ponds, and open water bodies. The built-up area consists of residential, industrial, roads, railways, and pavements. Vegetation includes plantations, cropland, and fallow land, such as both organized and unorganized lands. Barren lands are bare lands with sand deposits on river banks, open or vacant land, beaches, lakes, or ponds without water. Mangroves, backwaters, Reserve Forest are classified under forest classification. GEE is a fast and robust way to process large-volume remote sensing imagery with multi-source geospatial datasets and high-performance computational capability; hence, it is used to compute the LULC using RF classifier. Figure 4a (Z1) Fig. 4b (Z2) shows the LULC of the study.

The efficiency of the annual composites from GEE was evaluated using RF classification and precision tests from error matrices to validate the classification. The classification error matrix was generated for validation points and classified data. Thus the accuracy assessment was carried out for the classified LULC maps. The literature recommends the Kappa coefficient (KC) to measure and compare the accuracy for the image classification. Overall accuracy (OA), Producer accuracy (PA), and consumer accuracy (CA) derived from the confusion matrix are analyzed for each classification. Almost $80-90$ training samples were considered for each class in the classification, and similarly, 70-80 samples were evaluated for testing for the years 2009, 2015, and 2019. (Table 2)

Table 2 shows the consumers and producer accuracy for the calculated LULC 


\section{Consumer's accuracy (\%) Producer's accuracy (\%)}

\begin{tabular}{lllllll}
\hline LU/LC & $\mathbf{2 0 0 9}$ & $\mathbf{2 0 1 5}$ & $\mathbf{2 0 1 9}$ & $\mathbf{2 0 0 9}$ & $\mathbf{2 0 1 5}$ & $\mathbf{2 0 1 9}$ \\
\hline WATER & 100 & 100 & 100 & 100 & 98.91 & 100 \\
\hline SETTLEMENT & 97.33 & 96 & 98.07 & 77.66 & 84.7 & 82.25 \\
\hline VEGETATION & 93.10 & 91.8 & 83.33 & 100 & 100 & 92.3 \\
\hline FOREST & 100 & 100 & 93.1 & 96.07 & 77.14 & 67.5 \\
\hline BARREN & 77.66 & 89.8 & 82.14 & 97.33 & 96.12 & 98.57
\end{tabular}

The estimation of PA represents the accuracy of the specific class, while the estimate of CA reflects the user's belief in the classification. The CA is an essential variable for the classifications. In 2009 and 2019, the percentages of CA and PA for water bodies were 100 percent, while in 2015, CA was 100 percent, and PA was 98.91 percent. As a result, the waterbody's accuracy was more accurate compared to the other classes of the classification. The precision of CA and PA in the built-up class differed. The difference is between $10-20 \%$ per year, which could be due to a change in the ground control points for this class, which could have classified as incorrect. The CA in the vegetation class is highest in 2009, at 93.10 percent, and lowest in 2019, at 83.33 percent. Whereas the precision of PA is 100 percent in 2009 and 2015, it was 82.25 percent in 2019, and the difference may be due to the variations in the soil moisture. CA for the class forest is high in all three years, but the PA is comparatively low in 2015 and 2019. The vast distribution of CA in the barren land means that it is often mistaken with other LULC classes; the CA for $2009-2019$ indicates $77.6 \%-89.4 \%$, indicating that a few validity points did not come under this class, and this may be due to the similarity in the spectral properties of other classes. At the same time, PA is between $96-98 \%$, relatively higher. The $K C$ is often used to determine the dominance of one map over another. The total and class accuracies were quantified using KC. Table 3 shows the overall accuracy and Kappa coefficient for each year. The OA has been greater than $89 \%$ in all three years, with 2015 being the highest (94.03\%) and 2019 being the lowest (89.8\%). KC had the best rate in 2015, at $92.26 \%$. The year 2019 has a very low KC of about $87.07 \%$.

Table 3 Overall accuracy and Kappa statistics

\begin{tabular}{lll} 
Year & Overall Accuracy (\%) & Kappa Statistics (\%) \\
\hline $\mathbf{2 0 0 9}$ & 92.13 & 89.89 \\
\hline $\mathbf{2 0 1 5}$ & 94.03 & 92.26 \\
\hline $\mathbf{2 0 1 9}$ & 89.8 & 87.07 \\
\hline
\end{tabular}

\subsection{Analysis on CA Markov prediction}

The CA is associated with improved outcomes for modeling land-use changes with the integration of the Markov Chain model. Markov chain analysis is a useful method for evaluating land-use changes if the 
transitions can be described. A CA Markov is a framework that predicts the future based on the actual. It explains the LULC transition and forecasts a potential period for LULC based on the change. While developing any advanced analytics, factors that may affect land-use transition should be carefully analyzed. It must also be determined ahead of time-based on the research area's unique characteristics, the type of the models, and the analyses' goal $(\mathrm{Ku}, 2016)$. There is no widely accepted recommendation of driving factors for LULC changes, and each study area must be separately considered (V. Mishra et al., 2014). Transitions which has a significant impact on LULC changes are considered in this study. Six constraints transition driver variables are distance from road, and built-up, DEM, slope (Fig. 5), the spatial trend of change from barren land to built-up, and vegetation to built-up. Cramer's $V$ correlation is a method for identifying the correlation between driving forces and land use that employs a Multi-Criteria Evaluation (MCE). Distance from road has a high Cramer's $V$ correlation of 0.62 among all other variables, and it remains a stable variable that reflects essential suitability for the transition LULC change.

The LULC map for 2019 was forecasted using the driver variables with the earlier (2009) and later land cover images (2015). The validation module of TerrSet was used to statistically evaluate the quality of the 2019 forecasted map with that of the actual 2019 map. The transition probability matrix obtained is fed into the change demand modeling for the generation of the 2019 forecasted map. The validation tab is used to validate the accuracy of the forecasted 2019 map with that of the actual 2019 map. The disagreement of a grid cell is characterized as the disagreement caused by the comparison map failing to specify the grid cell positions precisely. Disagreement related to quantity is characterized as the amount of disagreement caused by the reference map failing to precisely determine the correct quantity and category by the reference map (Pontius \& Millones, 2011; Shade \& Kremer, 2019).

CA-Markov model is an empirical/statistical model that extrapolates measurable transition trends in the past years using driving forces generated through proximate causes. It is seen to be effective at modeling several and dynamic LULC transitions. The predicted maps were shown in the Fig. 6 for zone 1 and zone 2 .

\section{Discussion}

\subsection{Discussion on LULC change patterns}

Remote sensing is rapidly expanding due to new earth observation satellites, vast libraries of accessible data, and expanded computing capacity. GEE has been booming because it is a freely available cloudbased geospatial analysis and modeling tool that allow users to view, observe, and interpret geospatial data for many applications. The use of $\mathrm{ML}$ algorithms in combination with geographic object-oriented analysis techniques is expanding rapidly for GEE, where it is an effective environment for creating multitemporal composite images and implementing complex image processing and classification processes in a simple way. Urban expansion is linked to five major factors: rural-urban migration, new employment prospects, improving quality of life, natural development, and urban redefinition (Bank, 2007; Kafy et al., 2021). Obtained results were discussed as zone 1 and zone 2 for analysis. 
The overall area of zone 1 is 3842.8 Sq.km, and it includes the districts of Tiruvallur, Chennai, and Kanchipuram. The change statistics in table 4 and Fig. 7 show the change in the area for each class in their respective years. Water bodies were 237.4 Sq.km in 2009 and 198.2 Sq.km in 2019; this indicates a declining trend. The built-up class has been opposite to that of water bodies because it grows over time. In 2009, it was 382.4 Sq.km; in 2015, it was 424 Sq.km; and in 2019, it increased to 462.2 Sq.km. From 2009 to 2019 , the vegetation and forest classifications increased by $25.12 \%$ and $18.25 \%$, respectively. Between 2009 and 2019, the amount of barren land decreased by $12.56 \%$.

Over the year, the area has evolved to a greater extent, and recent studies also confirmed this Chennai is one of the fastest-growing cities in India. The main reason for urban growth is the IT sector; industrial areas are developed in this region as harbor facilitated the mode of transformation and evident from the LULC map of the cluster. The construction of residential, commercial, and metro structures and industrial estates led to the conversion of barren land to built-up land and its expansion to the west. The increase in vegetation class may be due to the climatic parameters influencing the barren land filled with greenness. This region has faced multiple disasters such as Tsunami, floods, cyclones, and experiencing a sea-level rise. It has several lake systems, including Pulicat, Puzhal, and Chembarambakkam Lake, which are used for different commercial and non-commercial purposes; the changes in these locations are the consequence of encroachments. The intensity of precipitation during the northeast monsoon has a detrimental impact on the transition from vegetation and barren land to waterbodies. According to the forecast, the barren and vegetated landscapes around Kanchipuram, near Chennai, are more likely to be built.

Table 4 Change in area for zone 1

\begin{tabular}{llll}
\multicolumn{4}{l}{ Area $(\mathrm{Sq} . \mathrm{Km})$} \\
\hline LULC & 2009 & $\mathbf{2 0 1 5}$ & $\mathbf{2 0 1 9}$ \\
\hline WATER & 237.492 & 227.250 & 198.208 \\
\hline SETTLEMENT & 382.482 & 424.053 & 462.200 \\
\hline VEGETATION & 965.368 & 1164.062 & 1207.931 \\
\hline FOREST & 2.240 & 2.280 & 2.649 \\
\hline BARREN & 2255.242 & 2025.184 & 1971.845
\end{tabular}

Zone 2

The regions of Villupuram, Cuddalore district, and Pondicherry union territory constitute zone 2, which is 2604.29 Sq.km. The change statistics in table 5 and Fig. 8 show the change in the area of each class in their respective years. Likewise, the zone 1, the water body shows a decreasing trend. In 2009 it was 
102.8 Sq.km and decreased to 74.5 Sq. Km in 2015, and further continued the trend till 2019 to 59.3 Sq.km. Built-up has doubled from 68.8 Sq. Km in 2009 to 143.4 Sq. Km in 2019. The vegetation shows a decreasing trend in zone 2 in contrast with an increasing trend in zone 1. From 2009 to 2019, the percentages of forest and barren land increased to $7.16 \%$ and $50.42 \%$, respectively.

Vanur, Marakkanam blocks come under the study region from Villupuram district, where these two areas have the highest rainfall in the district. And from the change analysis, these regions alternatively dominant with barren land and vegetation class. The kaliveli lake changes can be visually seen, and this is due to the dominant climatic parameters. The Cuddalore area is well-known for being one of Tamil Nadu's most flood- and cyclone-prone districts, resulting in huge vegetation loss and clogging of water in the built-up and barren land. Pondicherry is a tourist destination that has seen rapid development, necessitating the construction of numerous structures like high residential and commercial units. The new port construction and airport expansion led to a growing number of highways and residential areas around the area.

Table 5 Change in area for zone 2

\begin{tabular}{lllll}
\multicolumn{4}{c}{ Area (Sq.km) } \\
\cline { 2 - 5 } & LULC & $\mathbf{2 0 0 9}$ & $\mathbf{2 0 1 5}$ & $\mathbf{2 0 1 9}$ \\
\hline WATER & 102.84 & 74.53 & 59.35 \\
\hline SETTLEMENT & 68.85 & 113.99 & 143.44 \\
\hline VEGETATION & 1385.33 & 1102.47 & 830.35 \\
\hline FOREST & 9.63 & 9.99 & 10.32 \\
\hline BARREN & 1037.63 & 1303.31 & 1560.84 \\
4.2 Validation and Forecasting & LULC dynamic patterns
\end{tabular}

The CA-MC model has been used in the study to predict LULC transitions. From the early and later image inputs combined with the driver variables, the LULC map for 2019 is simulated. The simulation results for 2019 were compared to the classified 2019 LULC results. The CA-MC model produced the best results; therefore, the results for 2025 and 2030 are forecasted.

Validation from classified and projected for 2019 LULC zone 1 and zone 2

In this analysis, the kappa statistical validation approach was utilized to assess the reliability of the predicted LULC 2019. The statistics of change and \% accuracy assessment for each class for zone 1 and zone 2 are presented in Table 6. The accuracy of the water bodies in zones 1 and 2 was $83.2 \%$ and $92.4 \%$. The accuracy of built-up in zone 1 and zone 2 is about $98.9 \%$ and $92.3 \%$, respectively. Vegetation in zone 1 , with around $99.31 \%$, is very precise, and in zone 2 , with less precision, with $70.5 \%$. In both 
areas, forests have a precision of above $90 \%$. The accuracy of Barren land class in zone 1 is $99.1 \%$ and $84.7 \%$ for zone 2 in the predicted LULC 2019.

Table 6 area of change statics and accuracy assessment percentage

\begin{tabular}{|lllllll|}
\hline LULC & Zone1 & Cone 2 & & \\
\cline { 2 - 5 } & $\begin{array}{l}\text { Predicted } \\
\mathbf{2 0 1 9}\end{array}$ & $\begin{array}{l}\text { Classified } \\
\mathbf{2 0 1 9}\end{array}$ & $\begin{array}{l}\text { Accuracy } \\
\mathbf{( \% )}\end{array}$ & $\begin{array}{l}\text { Predicted } \\
\mathbf{2 0 1 9}\end{array}$ & $\begin{array}{l}\text { Classified } \\
\mathbf{2 0 1 9}\end{array}$ & $\begin{array}{l}\text { Accuracy } \\
\text { (\%) }\end{array}$ \\
\hline Water & 198.2 & 231.4 & 83.2 & 59.3 & 63.9 & 92.4 \\
\hline Built-up & 462.2 & 456.9 & 98.9 & 143.4 & 132.5 & 92.3 \\
\hline Vegetation & 1207.9 & 1199.6 & 99.31 & 830.3 & 1074.7 & 70.5 \\
\hline Forest & 2.6 & 2.5 & 90.9 & 10.3 & 10.1 & 97.8 \\
\hline Barren & 1971.8 & 1952.4 & 99.1 & 1560.8 & 1323.1 & 84.7 \\
\hline
\end{tabular}

\section{Conclusion}

In the present study, LULC change using the LCM of TerrSet Geospatial Monitoring and Modelling system was used. GEE was used to identify the LULC because it has a cloud platform, a user-friendly interface, and an effective scripting language, and it has a high degree of adaptability and flexibility. It is not easy to map LULC using a single or even monthly composite imagery. Mosaicking, stacking, and filtering images to produce a satisfactory land cover map from remotely sensed images have become simple as GEE has evolved. The Random Forest classifier tested well, and CA-MC produced results with acceptable accuracies; we studied the LULC for 2009, 2015, and 2019 and forecasted LULC for 2025 and 2030. This simulation focuses on the extent and direction of potential change on spatial and quantitative consequences of urban sprawl. Transition and rapid industrialization are major factors in development. The area of forest class will continue to grow, but the agricultural class will decrease compared to other classes. The historical records of land cover change clarified the rate of encroachment of urban areas on some other land cover, with dispersed patches of urban growth classifying the urban sprawl in the metro city. The climatic parameters indirectly influence the changes such one example is the beach varies according to the tide and tidal variation. Based on the sensitivity consideration, a buffer zone must be included to limit development in those fields. The results of this analysis can be adapted for city future development plans that city authorities, project planners, and other organizations can use in decisionmaking for LULC policies for sustainable development, resource management, and public planning.

\section{Declarations}

Acknowledgements: The authors would like to thank Google Earth Engine for the free computational resources of Landsat data. 
Author contribution : Devanantham Abijith- writing - original draft, software, data curation, analysing the results. Subbarayan Saravanan: Conceptualization, methodology, supervision, reviewing and editing the article.

Funding There was no funding provided for the work.

Availability of data and materials The data used in this research are available by the corresponding author upon reasonable request.

Ethics approval The authors confirm that this article is original research and has not been published or presented previously in any journal or conference in any language in whole or in part).

Consent to participate Not applicable

Consent for publication Not applicable.

Competing interests The authors declare no competing interests.

\section{References}

1. Abdi AM (2020) Land cover and land use classification performance of machine learning algorithms in a boreal landscape using Sentinel-2 data. GIScience Remote Sensing 57(1):1-20. https://doi.org/10.1080/15481603.2019.1650447

2. Aburas MM, Ho YM, Ramli MF, Ash'aari ZH (2017) Improving the capability of an integrated CAMarkov model to simulate spatio-temporal urban growth trends using an Analytical Hierarchy Process and Frequency Ratio. Int J Appl Earth Obs Geoinf 59:65-78. https://doi.org/10.1016/j.jag.2017.03.006

3. Al-sharif AAA, Pradhan B (2014) Monitoring and predicting land use change in Tripoli Metropolitan City using an integrated Markov chain and cellular automata models in GIS. Arab J Geosci 7(10):4291-4301. https://doi.org/10.1007/s12517-013-1119-7

4. Alam A, Bhat MS, Maheen M (2020) Using Landsat satellite data for assessing the land use and land cover change in Kashmir valley. GeoJournal 85(6):1529-1543. https://doi.org/10.1007/s10708-01910037-x

5. Ansari A, Golabi MH (2019) Prediction of spatial land use changes based on LCM in a GIS environment for Desert Wetlands - A case study: Meighan Wetland, Iran. International Soil Water Conservation Research 7(1):64-70. https://doi.org/10.1016/j.iswcr.2018.10.001

6. Bank W (2007) Bangladesh - Dhaka: Improving Living Conditions for the Urban Poor. https://openknowledge.worldbank.org/handle/10986/7686

7. Becker WR, Ló TB, Johann JA, Mercante E (2021) Statistical features for land use and land cover classification in Google Earth Engine. Remote Sensing Applications: Society Environment 21:100459. https://doi.org/10.1016/j.rsase.2020.100459 
8. Bose A, Chowdhury IR (2020) Monitoring and modeling of spatio-temporal urban expansion and land-use/land-cover change using markov chain model: a case study in Siliguri Metropolitan area, West Bengal, India. Modeling Earth Systems Environment 6(4):2235-2249. https://doi.org/10.1007/s40808-020-00842-6

9. Breiman L (1996) Bagging predictors. Mach Learn 24(2):123-140. https://doi.org/10.1007/bf00058655

10. Breiman L (1999) RANDOM FORESTS-RANDOM FEATURES

11. Cao J, Zhang Z, Luo Y, Zhang L, Zhang J, Li Z, Tao F (2021) Wheat yield predictions at a county and field scale with deep learning, machine learning, and google earth engine. European Journal of Agronomy, 123. https://doi.org/10.1016/j.eja.2020.126204

12. Chakraborty A, Sachdeva K, Joshi PK (2016) Mapping long-term land use and land cover change in the central Himalayan region using a tree-based ensemble classification approach. Appl Geogr 74:136-150. https://doi.org/10.1016/j.apgeog.2016.07.008

13. Chaudhuri G, Clarke KC (2014) Temporal Accuracy in Urban Growth Forecasting: A Study Using the SLEUTH Model. Trans GIS 18(2):302-320. https://doi.org/10.1111/tgis.12047

14. Chughtai AH, Abbasi $H$, Karas IR (2021) A review on change detection method and accuracy assessment for land use land cover. Remote Sensing Applications: Society Environment 22:100482. https://doi.org/10.1016/j.rsase.2021.100482

15. Colkesen I, Kavzoglu T (2017) Ensemble-based canonical correlation forest (CCF) for land use and land cover classification using sentinel-2 and Landsat OLI imagery. Remote Sensing Letters 8(11):1082-1091. https://doi.org/10.1080/2150704X.2017.1354262

16. Cunha ER, da, Santos CAG, Silva RM, da, Bacani VM, Pott A (2021) Future scenarios based on a CAMarkov land use and land cover simulation model for a tropical humid basin in the Cerrado/Atlantic forest ecotone of Brazil. Land Use Policy, 101. https://doi.org/10.1016/j.landusepol.2020.105141

17. de Jong SM, Shen Y, de Vries J, Bijnaar G, van Maanen B, Augustinus P, Verweij P (2021) Mapping mangrove dynamics and colonization patterns at the Suriname coast using historic satellite data and the LandTrendr algorithm. Int J Appl Earth Obs Geoinf 97:102293.

https://doi.org/10.1016/j.jag.2020.102293

18. Foody GM (2002) Status of land cover classification accuracy assessment. In Remote Sensing of Environment (Vol. 80, 1, pp 185-201). Elsevier Inc. https://doi.org/10.1016/S0034-4257(01)00295-4

19. Ghosh P, Mukhopadhyay A, Chanda A, Mondal P, Akhand A, Mukherjee S, Nayak SK, Ghosh S, Mitra D, Ghosh T, Hazra S (2017) Application of Cellular automata and Markov-chain model in geospatial environmental modeling- A review. Remote Sensing Applications: Society Environment 5:64-77. https://doi.org/10.1016/j.rsase.2017.01.005

20. Gibson L, Münch Z, Palmer A, Mantel S (2018) Future land cover change scenarios in South African grasslands - implications of altered biophysical drivers on land management. Heliyon 4(7):e00693. https://doi.org/10.1016/j.heliyon.2018.e00693 
21. Gorelick N, Hancher M, Dixon M, llyushchenko S, Thau D, Moore R (2017a) Google Earth Engine: Planetary-scale geospatial analysis for everyone. Remote Sens Environ 202:18-27. https://doi.org/10.1016/j.rse.2017.06.031

22. Gorelick N, Hancher M, Dixon M, llyushchenko S, Thau D, Moore R (2017b) Google Earth Engine: Planetary-scale geospatial analysis for everyone. Remote Sens Environ 202:18-27. https://doi.org/10.1016/j.rse.2017.06.031

23. Hasan S, Shi W, Zhu X, Abbas S, Khan HUA (2020) Future Simulation of Land Use Changes in Rapidly Urbanizing South China Based on Land Change Modeler and Remote Sensing Data. Sustainability 12(11):4350. https://doi.org/10.3390/su12114350

24. Hu Y, Zhang Q, Zhang Y, Yan H (2018) A deep convolution neural network method for land cover mapping: A case study of Qinhuangdao, China. Remote Sensing 10(12):1-17. https://doi.org/10.3390/rs10122053

25. Huang H, Chen Y, Clinton N, Wang J, Wang X, Liu C, Gong P, Yang J, Bai Y, Zheng Y, Zhu Z (2017) Mapping major land cover dynamics in Beijing using all Landsat images in Google Earth Engine. Remote Sens Environ 202:166-176. https://doi.org/10.1016/j.rse.2017.02.021

26. Ji H, Li X, Wei X, Liu W, Zhang L, Wang L (2020) Mapping 10-m resolution rural settlements using multi-source remote sensing datasets with the google earth engine platform. Remote Sensing 12(17):1-23. https://doi.org/10.3390/rs12172832

27. Kafy A-A, Naim MNH, Subramanyam G, Faisal A-A-, Ahmed NU, Rakib A, Al, Kona MA, Sattar GS (2021) Cellular Automata approach in dynamic modelling of land cover changes using RapidEye images in Dhaka, Bangladesh. Environmental Challenges 4:100084.

https://doi.org/10.1016/j.envc.2021.100084

28. Khan R, Gilani H (2021) Global drought monitoring with big geospatial datasets using Google Earth Engine. Environ Sci Pollut Res. https://doi.org/10.1007/s11356-020-12023-0

29. Ku CA (2016) Incorporating spatial regression model into cellular automata for simulating land use change. Appl Geogr 69:1-9. https://doi.org/10.1016/j.apgeog.2016.02.005

30. Kumar L, Mutanga O (2018) Google Earth Engine Applications Since Inception: Usage, Trends, and Potential. Remote Sensing 10(10):1509. https://doi.org/10.3390/rs10101509

31. Megahed Y, Cabral P, Silva J, Caetano M (2015) Land Cover Mapping Analysis and Urban Growth Modelling Using Remote Sensing Techniques in Greater Cairo Region-Egypt. ISPRS International Journal of Geo-Information 4(3):1750-1769. https://doi.org/10.3390/ijgi4031750

32. Midekisa A, Holl F, Savory DJ, Andrade-Pacheco R, Gething PW, Bennett A, Sturrock HJW (2017) Mapping land cover change over continental Africa using Landsat and Google Earth Engine cloud computing. PLoS ONE, 12(9). https://doi.org/10.1371/journal.pone.0184926

33. Mishra VN, Rai PK (2016) A remote sensing aided multi-layer perceptron-Markov chain analysis for land use and land cover change prediction in Patna district (Bihar), India. Arab J Geosci 9(4):1-18. https://doi.org/10.1007/s12517-015-2138-3 
34. Mishra V, Rai P, Mohan K (2014) Prediction of land use changes based on land change modeler (LCM) using remote sensing: A case study of Muzaffarpur (Bihar), India. Journal of the Geographical Institute Jovan Cvijic SASAZbornik Radova Geografskog Instituta Jovan Cvijic SANU 64(1):111-127. https://doi.org/10.2298/ijgi1401111m

35. Müller K, Steinmeier C, Küchler M (2010) Urban growth along motorways in Switzerland. Landscape Urban Planning 98(1):3-12. https://doi.org/10.1016/j.landurbplan.2010.07.004

36. Nath B, Wang Z, Ge Y, Islam K, Singh RP, Niu Z (2020) Land use and land cover change modeling and future potential landscape risk assessment using Markov-CA model and analytical hierarchy process. ISPRS International Journal of Geo-Information, 9(2). https://doi.org/10.3390/ijgi9020134

37. Noszczyk T (2019) A review of approaches to land use changes modeling. In Human and Ecological Risk Assessment (Vol. 25, 6, pp 1377-1405). Taylor and Francis Inc.

https://doi.org/10.1080/10807039.2018.1468994

38. Ozturk D (2015) Urban growth simulation of Atakum (Samsun, Turkey) using cellular automataMarkov chain and Multi-layer Perceptron-Markov chain models. Remote Sensing 7(5):5918-5950. https://doi.org/10.3390/rs70505918

39. Parthasarathy KSS, Deka PC (2019) Remote sensing and GIS application in assessment of coastal vulnerability and shoreline changes: a review. ISH Journal of Hydraulic Engineering 00(00):1-13. https://doi.org/10.1080/09715010.2019.1603086

40. Parthasarathy KSS, Saravanan S, Deka PC, Devanantham A (2020) Assessment of potentially vulnerable zones using geospatial approach along the coast of Cuddalore district, East coast of India. ISH Journal of Hydraulic Engineering. https://doi.org/10.1080/09715010.2020.1753250

41. Pérez-Vega A, Mas JF, Ligmann-Zielinska A (2012) Comparing two approaches to land use/cover change modeling and their implications for the assessment of biodiversity loss in a deciduous tropical forest. Environ Model Softw 29(1):11-23. https://doi.org/10.1016/j.envsoft.2011.09.011

42. Pontius RG, Millones M (2011) Death to Kappa: Birth of quantity disagreement and allocation disagreement for accuracy assessment. In International Journal of Remote Sensing (Vol. 32, Issue 15, pp. 4407-4429). Taylor and Francis Ltd. https://doi.org/10.1080/01431161.2011.552923

43. Pourghasemi HR, Amiri M, Edalat M, Ahrari AH, Panahi M, Sadhasivam N, Lee S (2021) Assessment of Urban Infrastructures Exposed to Flood Using Susceptibility Map and Google Earth Engine. IEEE Journal of Selected Topics in Applied Earth Observations Remote Sensing 14:1923-1937. https://doi.org/10.1109/JSTARS.2020.3045278

44. Rodriguez-Galiano VF, Ghimire B, Rogan J, Chica-Olmo M, Rigol-Sanchez JP (2012) An assessment of the effectiveness of a random forest classifier for land-cover classification. ISPRS Journal of Photogrammetry Remote Sensing 67(1):93-104. https://doi.org/10.1016/j.isprsjprs.2011.11.002

45. Roy P, Roy A, Joshi P, Kale M, Srivastava V, Srivastava S, Dwevidi R, Joshi C, Behera M, Meiyappan P, Sharma Y, Jain A, Singh J, Palchowdhuri Y, Ramachandran R, Pinjarla B, Chakravarthi V, Babu N, Gowsalya M, ... Kushwaha D (2015) Development of Decadal (1985-1995-2005) Land Use and Land Cover Database for India. Remote Sensing 7(3):2401-2430. https://doi.org/10.3390/rs70302401 
46. Saranya T, Saravanan S (2020) Groundwater potential zone mapping using analytical hierarchy process (AHP) and GIS for Kancheepuram District, Tamilnadu, India. Modeling Earth Systems Environment 6(2):1105-1122. https://doi.org/10.1007/s40808-020-00744-7

47. Saranya T, Saravanan S (2021) Evolution of a hybrid approach for groundwater vulnerability assessment using hierarchical fuzzy-DRASTIC models in the Cuddalore Region, India. Environ Earth Sci 80(5):179. https://doi.org/10.1007/s12665-021-09479-9

48. Saxena A, Jat MK (2020) Land suitability and urban growth modeling: Development of SLEUTHSuitability. Computers, Environment and Urban Systems, 81(November 2019), 101475. https://doi.org/10.1016/j.compenvurbsys.2020.101475

49. Seydi ST, Akhoondzadeh M, Amani M, Mahdavi S (2021) Wildfire damage assessment over australia using sentinel-2 imagery and modis land cover product within the google earth engine cloud platform. Remote Sensing 13(2):1-30. https://doi.org/10.3390/rs13020220

50. Shade C, Kremer P (2019) Predicting Land Use Changes in Philadelphia Following Green Infrastructure Policies. Land 8(2):28. https://doi.org/10.3390/land8020028

51. Sidhu N, Pebesma E, Câmara G (2018a) Using Google Earth Engine to detect land cover change: Singapore as a use case. European Journal of Remote Sensing 51(1):486-500. https://doi.org/10.1080/22797254.2018.1451782

52. Sidhu N, Pebesma E, Câmara G (2018b) Using Google Earth Engine to detect land cover change: Singapore as a use case. European Journal of Remote Sensing 51(1):486-500. https://doi.org/10.1080/22797254.2018.1451782

53. Silva LPe, Xavier APC, da Silva RM, Santos CAG (2020) Modeling land cover change based on an artificial neural network for a semiarid river basin in northeastern Brazil. Global Ecology and Conservation, 21. https://doi.org/10.1016/j.gecco.2019.e00811

54. Singh L, Saravanan S, Jennifer JJ, Abijith D (2021) Application of multi-influence factor (MIF) technique for the identification of suitable sites for urban settlement in Tiruchirappalli City, Tamil Nadu, India. Asia-Pacific Journal of Regional Science, 1-27. https://doi.org/10.1007/s41685-02100194-8

55. Singh SK, Mustak S, Srivastava PK, Szabó S, Islam T (2015) Predicting Spatial and Decadal LULC Changes Through Cellular Automata Markov Chain Models Using Earth Observation Datasets and Geo-information. Environmental Processes 2(1):61-78. https://doi.org/10.1007/s40710-015-0062-x

56. Smith A (2010) Image segmentation scale parameter optimization and land cover classification using the Random Forest algorithm. Journal of Spatial Science 55(1):69-79. https://doi.org/10.1080/14498596.2010.487851

57. Soulard C, Albano C, Villarreal M, Walker J (2016) Continuous 1985-2012 Landsat Monitoring to Assess Fire Effects on Meadows in Yosemite National Park, California. Remote Sensing 8(5):371. https://doi.org/10.3390/rs8050371

58. Tamiminia H, Salehi B, Mahdianpari M, Quackenbush L, Adeli S, Brisco B (2020) Google Earth Engine for geo-big data applications: A meta-analysis and systematic review. ISPRS Journal of 
Photogrammetry Remote Sensing 164(May):152-170.

https://doi.org/10.1016/j.isprsjprs.2020.04.001

59. Tassi A, Vizzari M (2020) Object-Oriented LULC Classification in Google Earth Learning Algorithms. Remote Sensing 2020(12):3776

60. Tewabe D, Fentahun T (2020) Assessing land use and land cover change detection using remote sensing in the Lake Tana Basin, Northwest Ethiopia. Cogent Environmental Science, 6(1). https://doi.org/10.1080/23311843.2020.1778998

61. Thapa RB, Murayama Y (2011) Urban growth modeling of Kathmandu metropolitan region, Nepal. Comput Environ Urban Syst 35(1):25-34. https://doi.org/10.1016/j.compenvurbsys.2010.07.005

62. Tian H, Pei J, Huang J, Li X, Wang J, Zhou B, Qin Y, Wang L (2020) Garlic and winter wheat identification based on active and passive satellite imagery and the google earth engine in northern china. In Remote Sensing (Vol. 12, Issue 21, pp. 1-17). MDPI AG.

https://doi.org/10.3390/rs12213539

63. Tiwari V, Kumar V, Matin MA, Thapa A, Ellenburg WL, Gupta N, Thapa S (2020) Flood inundation mapping-Kerala 2018; Harnessing the power of SAR, automatic threshold detection method and Google Earth Engine. PLoS ONE, 15(8 August). https://doi.org/10.1371/journal.pone.0237324

64. Tsai Y, Stow D, Chen H, Lewison R, An L, Shi L (2018) Mapping Vegetation and Land Use Types in Fanjingshan National Nature Reserve Using Google Earth Engine. Remote Sensing 10(6):927. https://doi.org/10.3390/rs10060927

65. Wagle N, Acharya TD, Kolluru V, Huang H, Lee DH (2020) Multi-Temporal Land Cover Change Mapping Using Google Earth Engine and Ensemble Learning Methods. Applied Sciences 10(22):8083. https://doi.org/10.3390/app10228083

66. Yang X, Chen Y, Wang J (2020) Combined use of Sentinel-2 and Landsat 8 to monitor water surface area dynamics using Google Earth Engine. Remote Sensing Letters 11(7):687-696. https://doi.org/10.1080/2150704X.2020.1757780

67. Ye L, Liu M, Liu X, Zhu L (2021) Developing a new disturbance index for tracking gradual change of forest ecosystems in the hilly red soil region of southern China using dense Landsat time series. Ecological Informatics, 61. https://doi.org/10.1016/j.ecoinf.2021.101221

68. Zadbagher E, Becek K, Berberoglu S (2018) Modeling land use/land cover change using remote sensing and geographic information systems: case study of the Seyhan Basin, Turkey. Environ Monit Assess 190(8):1-15. https://doi.org/10.1007/s10661-018-6877-y

69. Zhang Z, Wei M, Pu D, He G, Wang G, Long T (2021) Assessment of annual composite images obtained by google earth engine for urban areas mapping using random forest. Remote Sensing 13(4):1-21. https://doi.org/10.3390/rs13040748

70. Zhang, Z., Wei, M., Pu, D., He, G., Wang, G., \& Long, T. (2021). Assessment of annual composite images obtained by google earth engine for urban areas mapping using random forest. Remote Sensing, 13(4), 1-21. https://doi.org/10.3390/rs13040748 

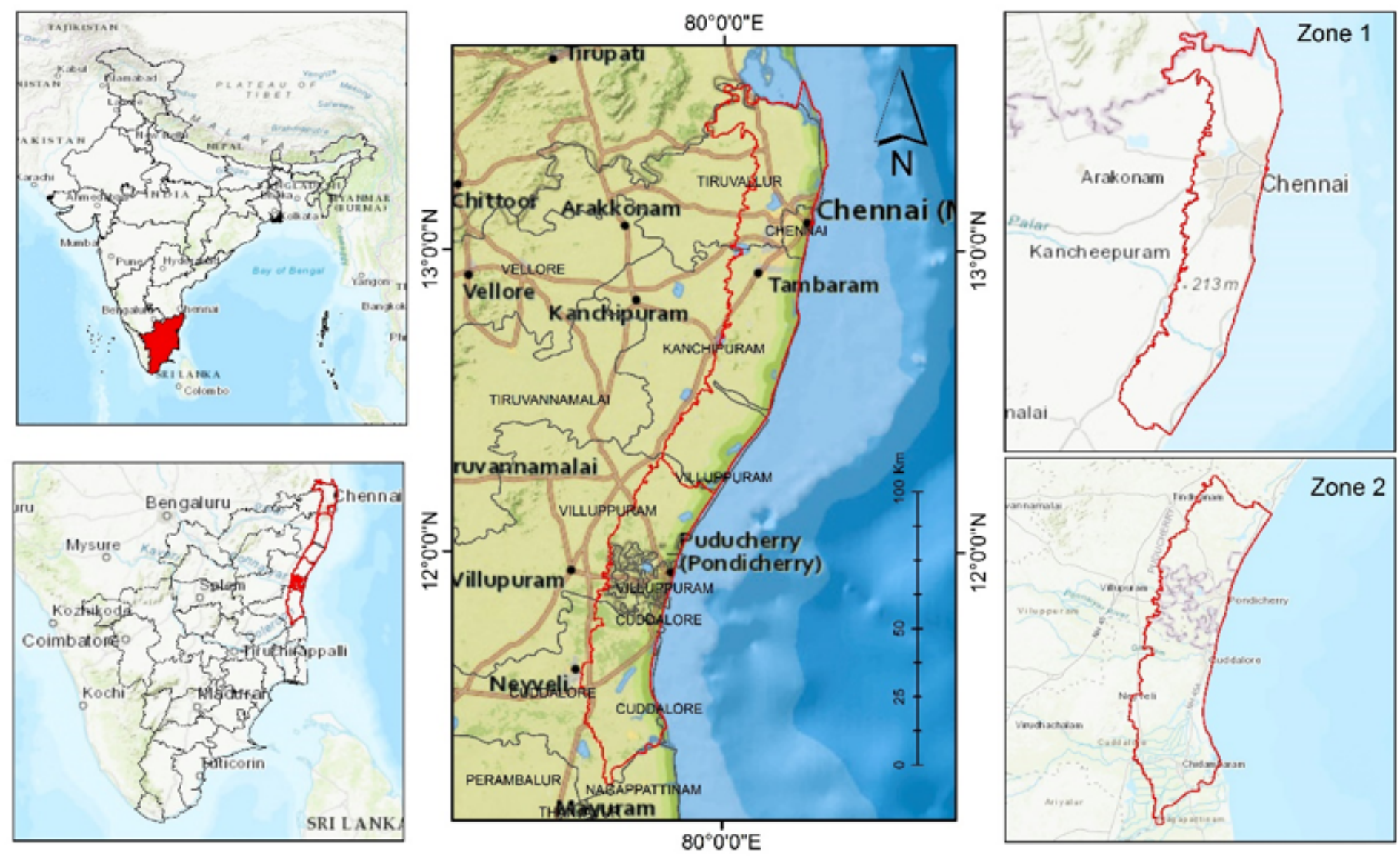

\section{Figure 1}

Key map of the study Note: The designations employed and the presentation of the material on this map do not imply the expression of any opinion whatsoever on the part of Research Square concerning the legal status of any country, territory, city or area or of its authorities, or concerning the delimitation of its frontiers or boundaries. This map has been provided by the authors. 


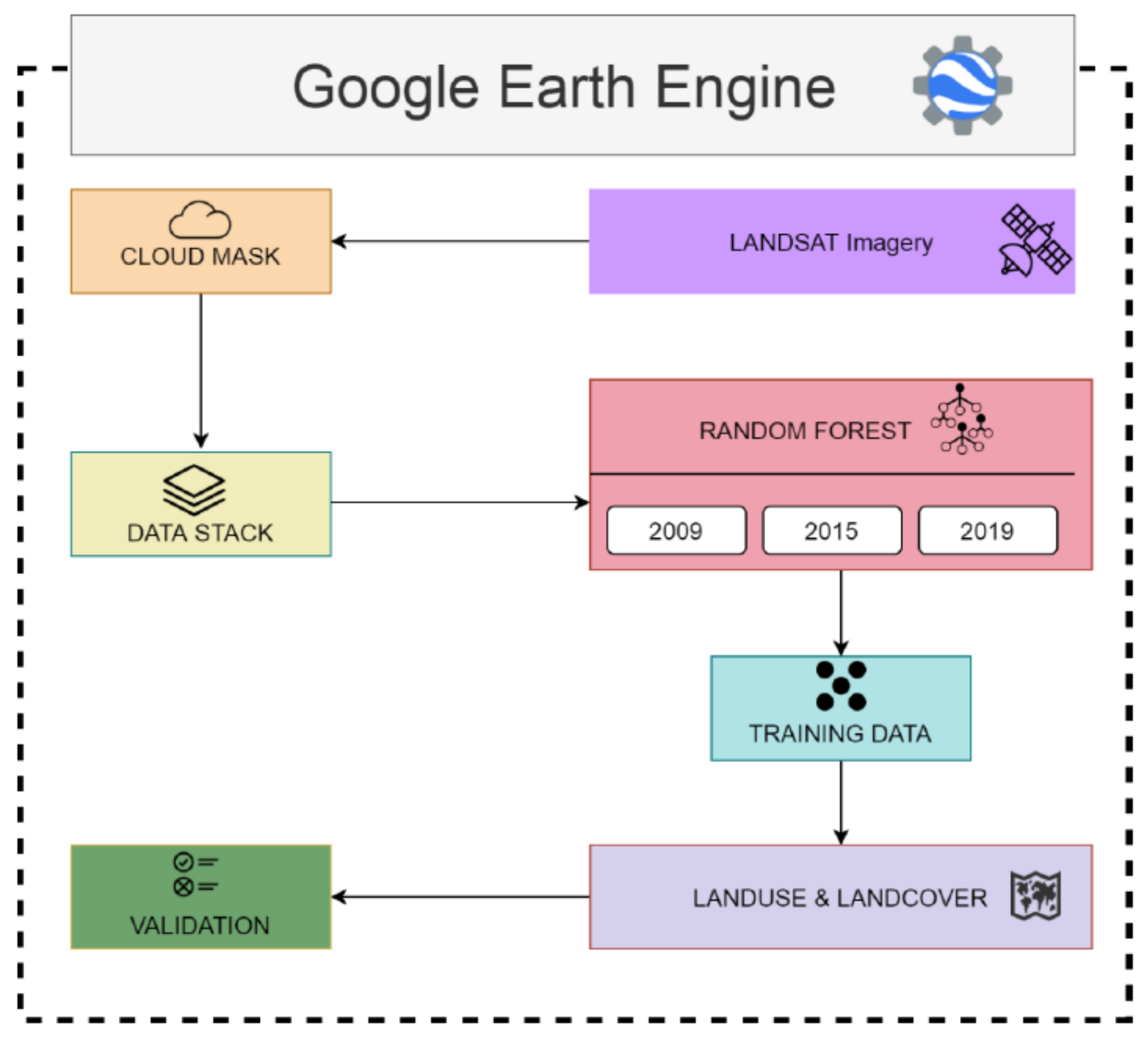

Figure 2

Process carried out in the GEE environment 


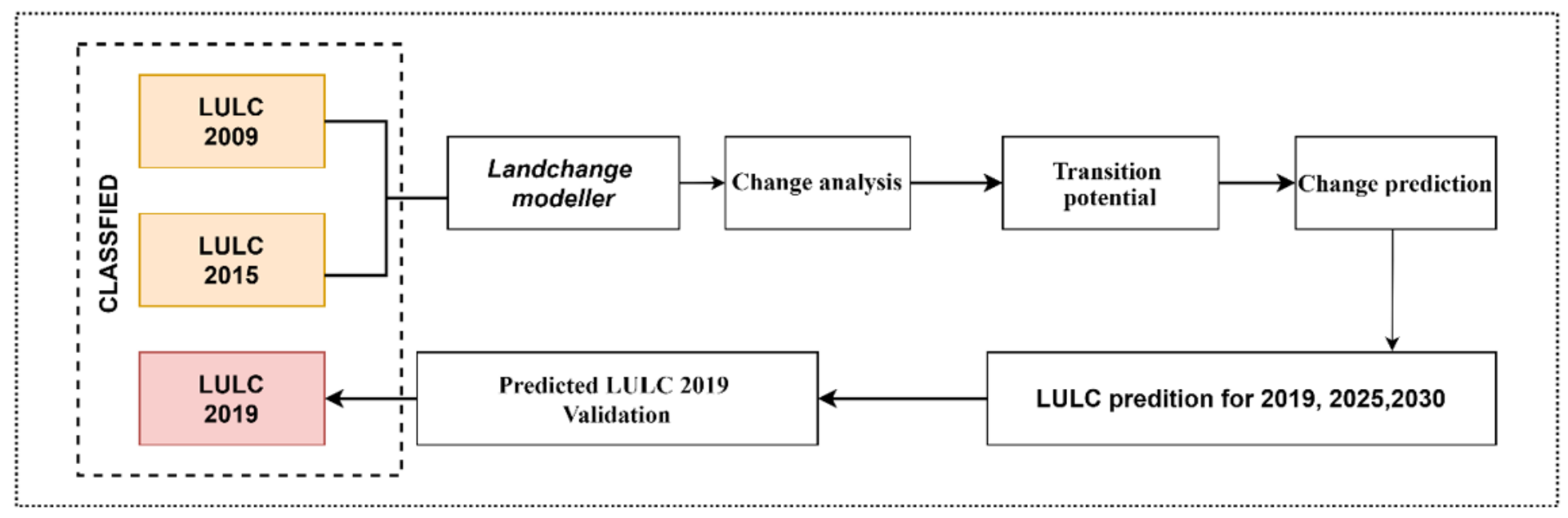

Figure 3

Process flowchart in LCM

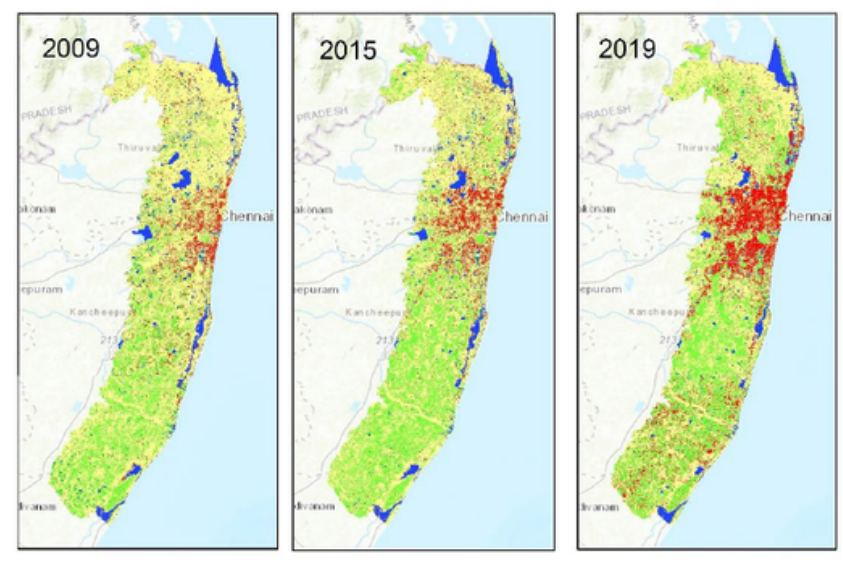

Water bodies Built up Vegetation $\square$ Forest Barren land

(a)
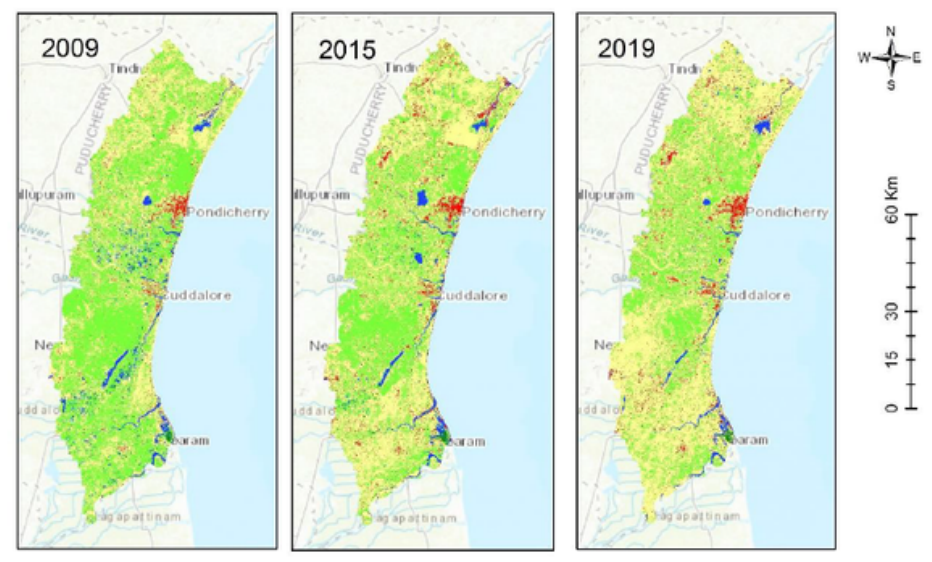

Water bodies Built up Vegetation Forest Barren land

(b)

Figure 4

(a) LULC map of zone 1 and 4(b) LULC map of zone 2 Note: The designations employed and the presentation of the material on this map do not imply the expression of any opinion whatsoever on the part of Research Square concerning the legal status of any country, territory, city or area or of its authorities, or concerning the delimitation of its frontiers or boundaries. This map has been provided by the authors. 

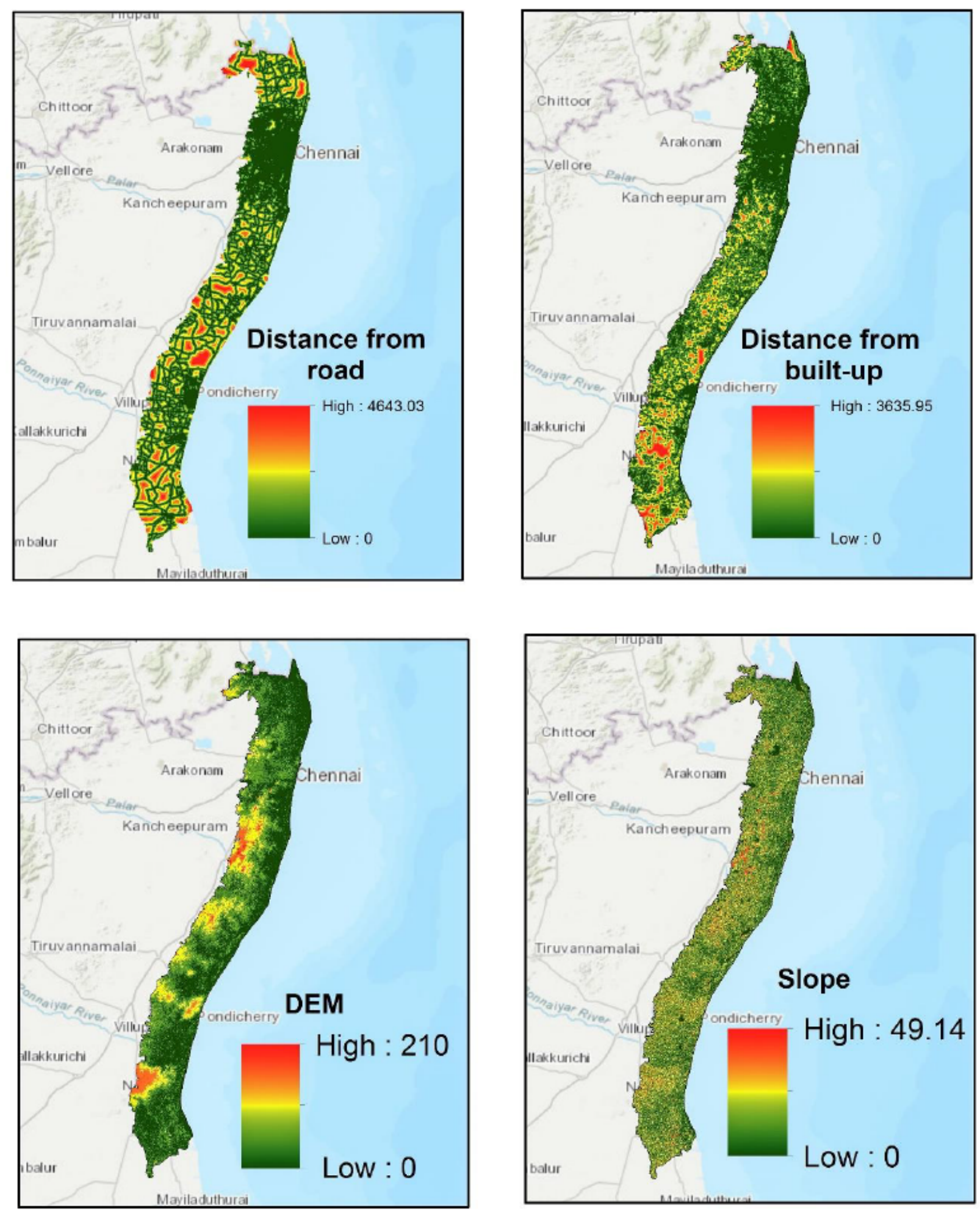

\section{Figure 5}

Transition driver variables for LULC prediction Note: The designations employed and the presentation of the material on this map do not imply the expression of any opinion whatsoever on the part of Research Square concerning the legal status of any country, territory, city or area or of its authorities, or concerning the delimitation of its frontiers or boundaries. This map has been provided by the authors. 

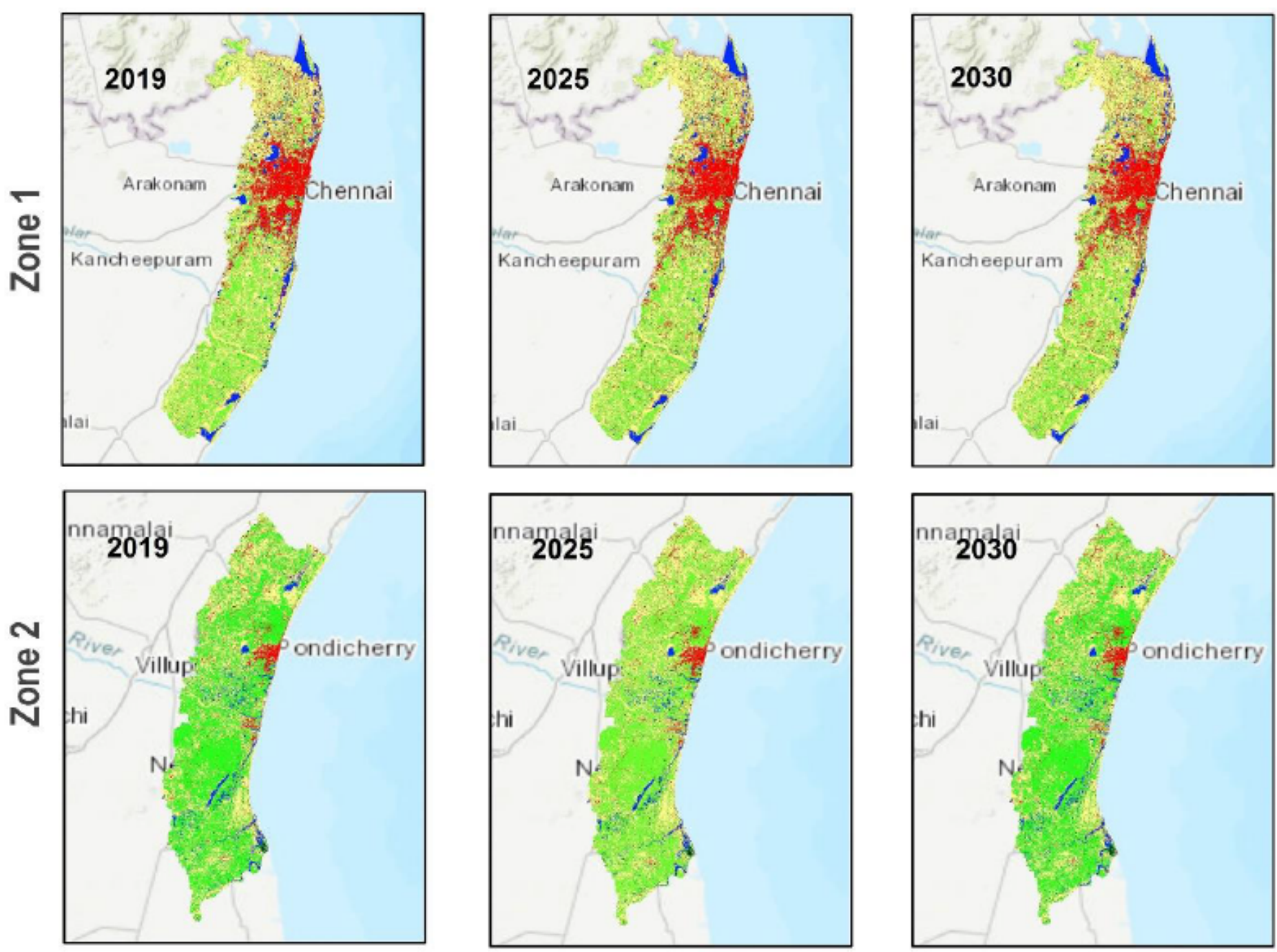

Predicted Landuse and Landcover

Water bodies

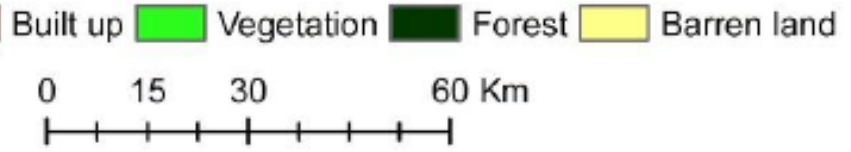

\section{Figure 6}

LULC forecast for 2025, LULC 2030 of the study region zone1 and zone 2 Note: The designations employed and the presentation of the material on this map do not imply the expression of any opinion whatsoever on the part of Research Square concerning the legal status of any country, territory, city or area or of its authorities, or concerning the delimitation of its frontiers or boundaries. This map has been provided by the authors. 


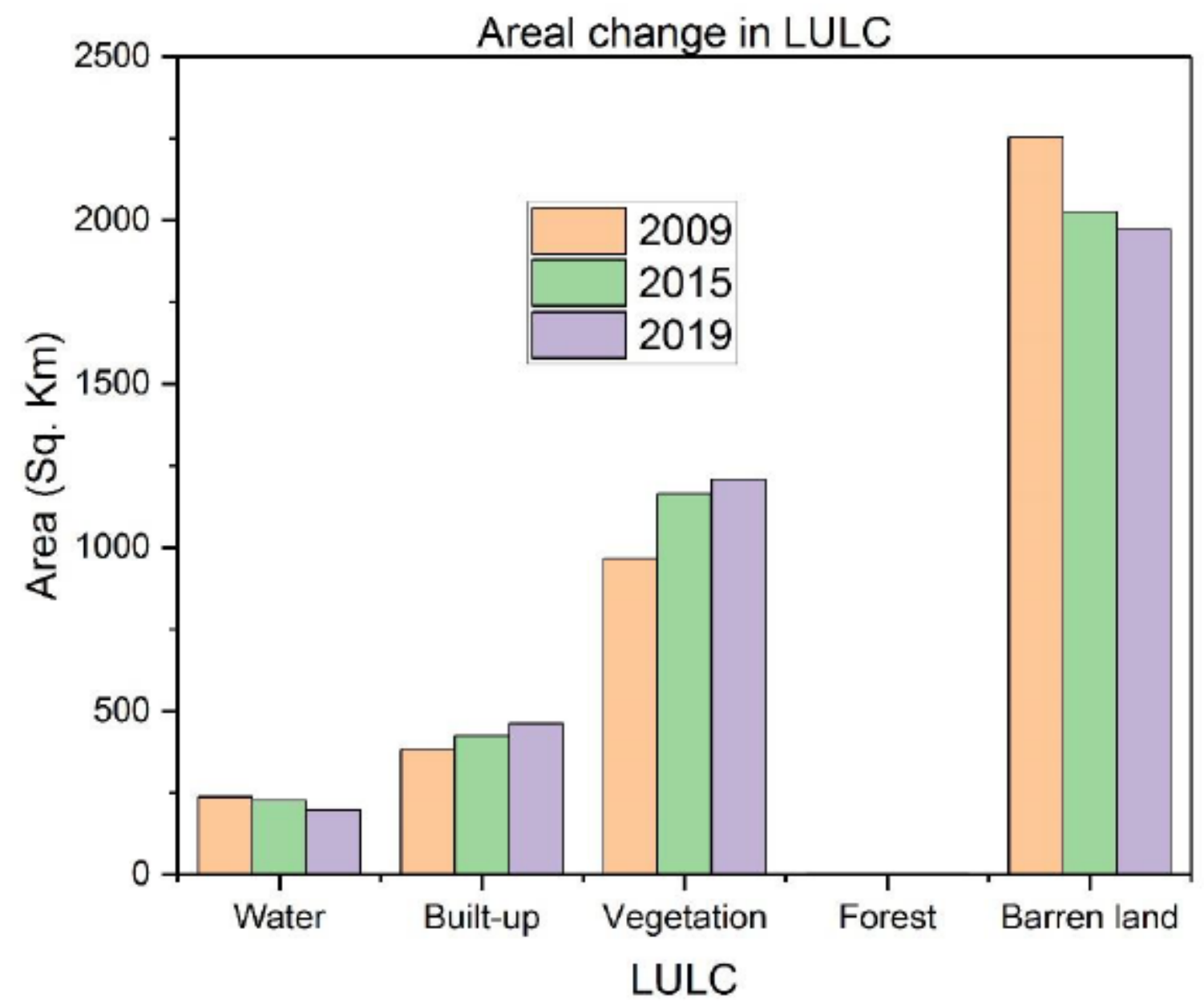

Figure 7

Change in area and class for zone 1 
Areal change in LULC

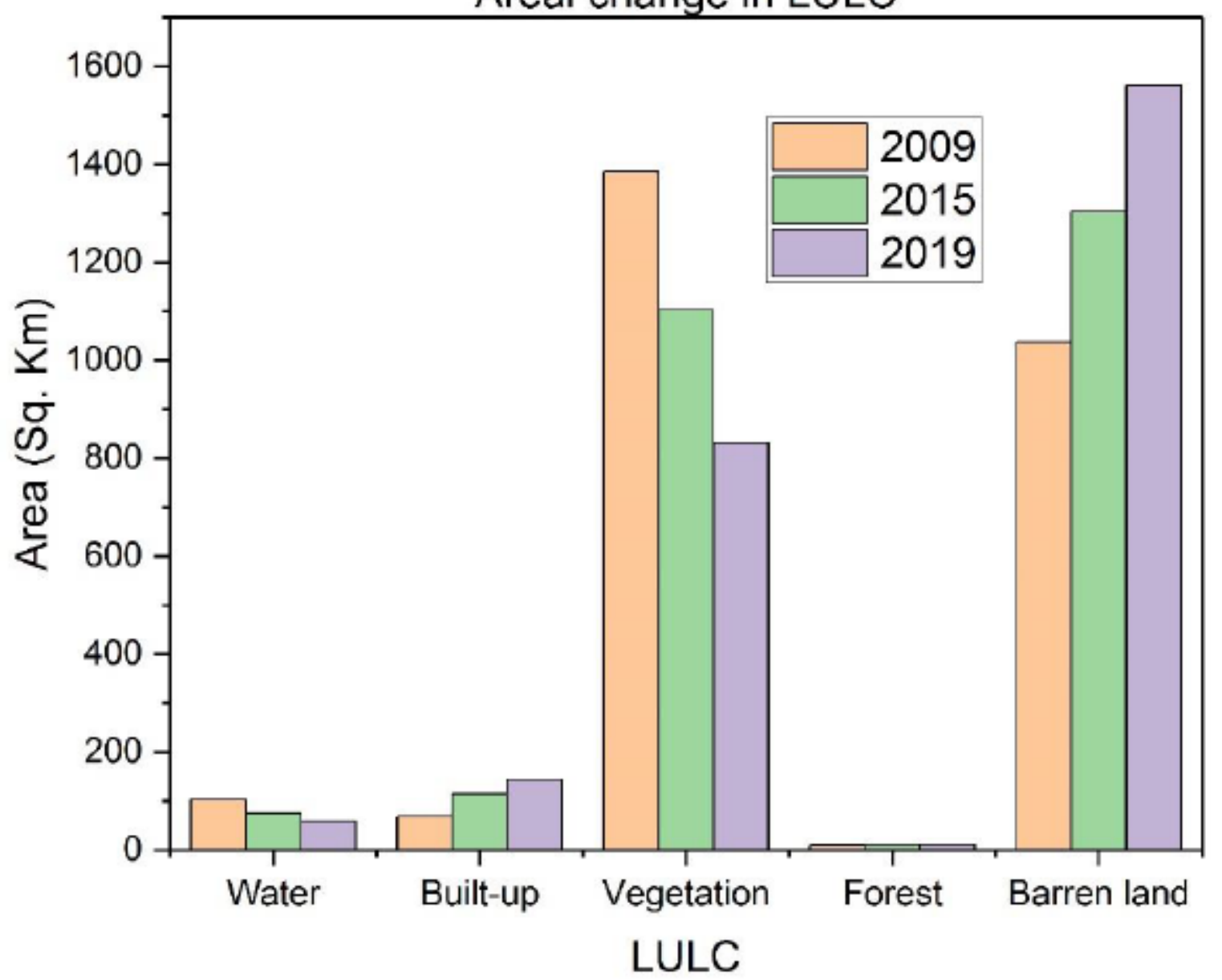

Figure 8

Change in area and class for zone 2 